\title{
Introducing the Alveolar Moulding Obturator (AMO): an appliance for the early management of Cleft Palate Neonates
}

\author{
SADJ April 2019, Vol. 74 No. 3 p 141 - p143
}

SM Dawjee', MM Dawjee ${ }^{2}$

\section{Keywords}

Cleft palate, alveolar moulding, cleft obturator, feeding plate.

Clefting of the lip and palate is one of the most common congenital malformations encountered worldwide. It affects about 1 to 1.6 per 1000 live births and is more common in males than in female,,$^{1-3}$ occurring more frequently on the left side than it does on the right side of the face. ${ }^{1,4}$ The condition can come as a severe emotional shock to parents, particularly in third world countries where prenatal detection is not affordable and parents cannot be sensitised before the birth of their child. Such emotional trauma can lead to a sense of blame, guilt and strained social relations at a time when family support is most needed. ${ }^{5}$

Early intervention into cleft management provides some emotional comfort and is helpful as the maxilla undergoes its greatest postnatal growth change during infancy and early childhood. ${ }^{6}$

Maxillary growth was found to be favourable in patients who waited the recommended period as compared with those who had early surgery. In addition, palatal dimensions were more nearly normal in the late group than in the early group. ${ }^{7}$

The 'rule of ten' (10 $\mathrm{g}$ haemoglobin, 10 weeks of age and 10 pounds of body weight) is usually applied to determine the timing of the surgical intervention in cases of congenital clefts. ${ }^{3,8}$ Adequate feeding and nutrition is therefore vital to meet this requirement.

While the six months waiting period prior to surgery is a medical recommendation, the delay may be psychologically challenging and stressful for the parents and family.

\section{Author affiliations:}

1. Salahuddien Mohamed Dawjee: $B C h D, B C h D$ Hons, MSc(Odont), MDent(Ortho), PGDip IRE, PhD, Head, Department of Orthodontics, University of Pretoria, South Africa.

2. Maryam Mohamed Dawjee: BChD, PG Dip Aesthetic Dentistry, MSc(Dent), Associate Aesthetic Dentist, Thandar Inc, Rosebank, Gauteng.

Corresponding author: Salahuddien M Dawjee

Department of Orthodontics, University of Pretoria. P.O. Box 1266

Pretoria, 0001. Email: s.dawjee@up.ac.za Tel: +27 (0)82 7786450

\section{ACRONYMS}

AMO: Alveolar Moulding Obturators

CAD: Computer Aided Design

Lip taping of the cleft lip and the use of intra-oral obturators/ feeding plates promote neonatal nursing and can have a reassuring and comforting outcome on the parents and family. ${ }^{9}$

Patients treated by presurgical orthopaedics such as obturators or feeding plates have been shown to have a higher probability of achieving favourable occlusal relationships than in those treated by surgical intervention only..$^{10}$

An obturator or feeding plate is an appliance fabricated from acrylic that seals the cleft, separates the oral and nasal cavities and permits effective deglutition without regurgitation or spillage of fluids through the nose. This appliance was designed by Hotz and has been modified considerably since its introduction. ${ }^{11}$

Acrylic obturators have generally been the appliance of choice for neonates presenting with a cleft palate.

Although claims have been made that these appliances can result in favourably reducing the cleft, there is no documented evidence to support this. Acrylic obturators are bulky in the confines of a neonate mouth and require periodic relining, rebasing and even replacement to conform to changes in growth. Acrylic carries the inherent risks in that it may irritate the mucosa and can compromise oral health by virtue of its porosity. The reline material has the potential to tear or fracture and the additional mass it introduces can negatively influence the retention of the appliance in the confines of a neonate mouth.

According to Bütow (1984), the infant tolerates the feeding plate well, and usually gives voice to displeasure at its removal for cleaning purposes. It is important that initially such a plate should be placed in the first two weeks of life, preferably in the first couple of hours after birth. ${ }^{8}$

Infants should not wear the obturator during the week prior to surgery so that the mucosa may be lesion-free and so resist any hyperplastic reaction. To limit the risk of complications the mucosa has to be as healthy as possible for the surgical reconstructive procedure. ${ }^{8}$ 
The adoption of computer technology and computer aided design (CAD) in particular, offers the potential to design obturators that may alter and direct tissue growth favourably in and around the cleft to facilitate surgical closure.

Invisalign $₫$ and Clearpath $\AA$ are orthodontic treatment modalities aimed at aligning teeth through the application of a series of modified thermoplastic occlusal guards (gum-guards). The appliances progressively effect selective and incremental changes in tooth position until the desired result is achieved. The appliances are made from a thermoplastic, viscoelastic material $1-3 \mathrm{~mm}$ thick that is heated and tightly suctioned over a study cast of the patient's mouth. The appliances are translucent, smooth, light weight and have an inherent elasticity which makes them self-retentive, eliminating the need for wire clasps or relines.

While successful in achieving tooth movement, the Invisalign $\AA$ and Clearpath $₫$ techniques have not been applied to the management of neonates with a cleft palate. This treatment modality may have significant value in the early stages of cleft palate management. It is therefore pertinent that the application of this treatment modality to cleft palate babies be explored.

From successive CAD modified images of the cleft palate (Figures 1 and 2), models can be printed and thermoplastic, viscoelastic Alveolar Moulding Obturators (AMO) may be constructed on the models.

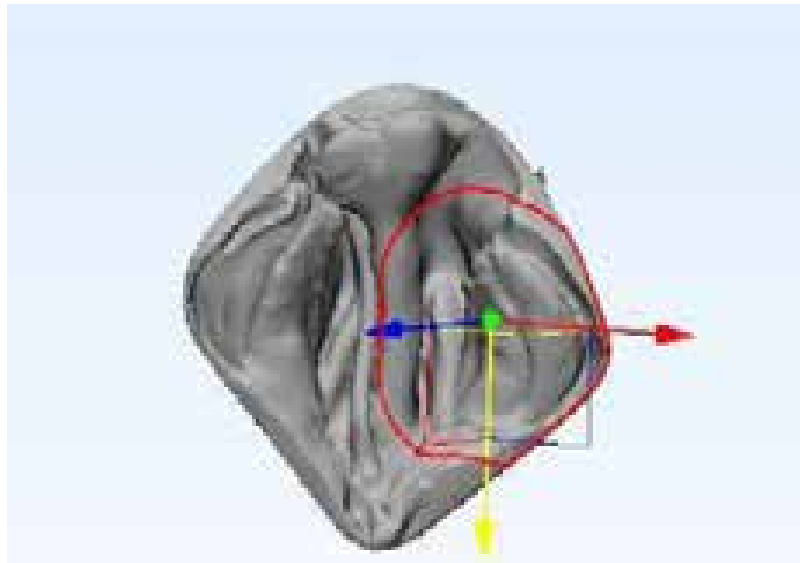

Figure 1. A digital representation of a study cast with arrows indicating the intended growth modification of the alveolar arches in a bucco-lingual and posterior direction to reduce the cleft size and align the prolabium.
A total of five AMOs fabricated from five progressively modified printed models are shown in Figure 3.

These should be supplied to the patient individually on a monthly basis and it is expected that the use of progressively modified obturators will approximate the alveolar arches and palatal cleft favourably in preparation for surgical repair. The AMO approach will provide that essential emotional comfort to patient and to parents, will minimise regurgitation and spillage, and should result in reduced surgical commitment.

The appliances are destined for clinical trial.

\section{References}

1. Operation Smile South Africa - About Us - Quick Facts Available at: http://southafrica.operationsmile.org/aboutus/ facts/. Accessed 7/30/2013, 2013.

2. Thornton JB, Nimer S, Howard PS. The incidence, classification, etiology, and embryology of oral clefts. Semin.Orthod. 1996;2(3):162-8.

3. Wilhelmsen HR, Musgrave $\mathrm{RH}$. Complications of cleft lip surgery. Cleft Palate J. 1966 Jul;3:223-31.

4. Presurgical orthopedic therapy for cleft lip and palate. Available at: http://emedicine.medscape.com/article/2036547-overview. Accessed 5/22/2013, 2013.

5. Brunner M, Georgopoulou A, Verres R, Komposch G, Mussig E. Psychosocial problems and coping strategies of young patients with cleft lip and palate. Psychother.Psychosom.Med. Psychol. 2004;54(11):423-30.

6. Krischer JP, O'Donnell JP, Shiere FR. Changing cleft widths: a problem revisited. Am.J.Orthod. $1975 ; 67(6): 647-59$.

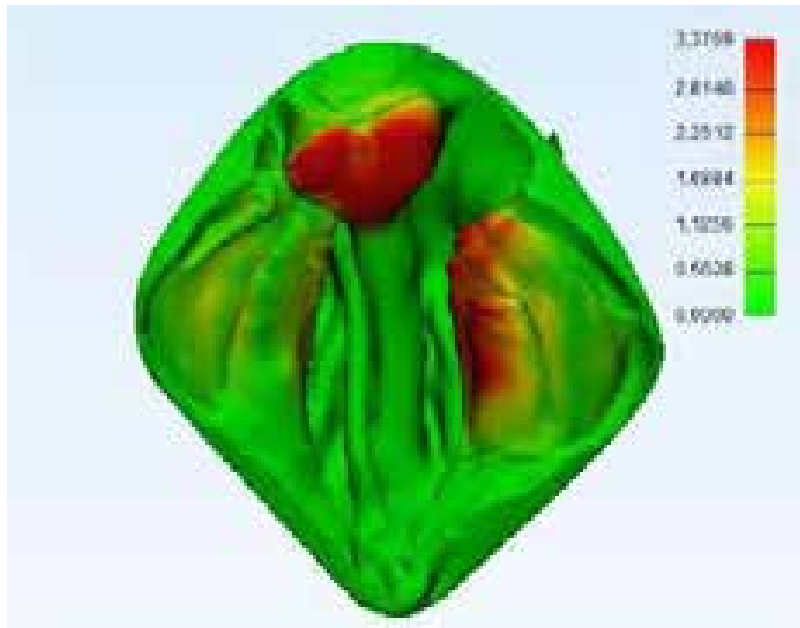

Figure 2. Computer aided design (CAD) analysis of a digital study cast for the production of progressively modified AMOs.

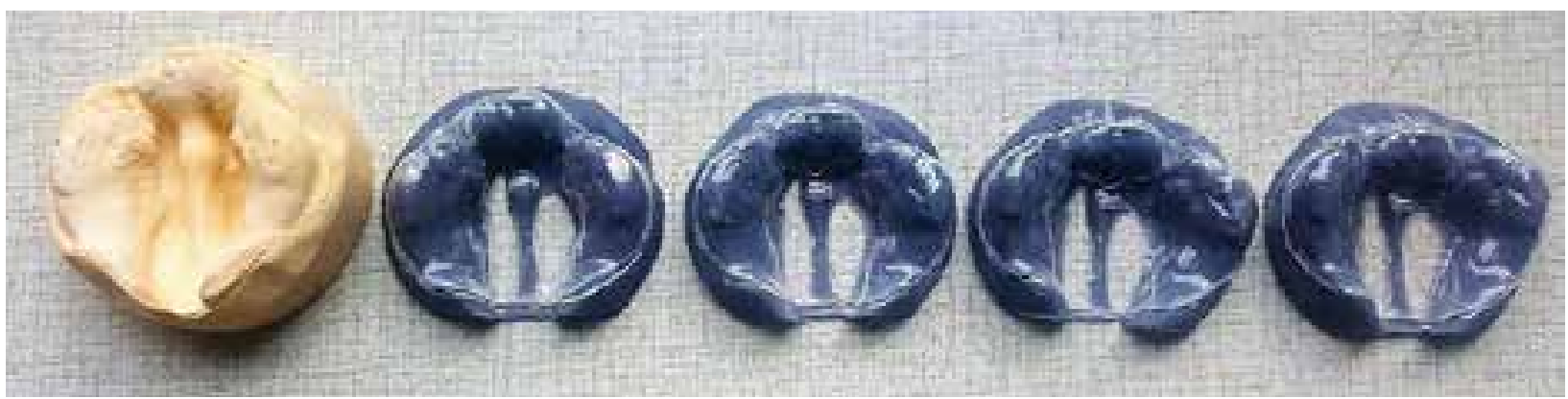

Figure 3. A series of AMOs made from digitally modified printed models. Note the progressive alignment of the segments. 
7. Laowansiri U, Behrents RG, Araujo E, Oliver DR, Buschang $\mathrm{PH}$. Maxillary growth and maturation during infancy and early childhood. Angle Orthod. 2013;83(4):563-571.

8. Bütow KW. Treatment of cleft lip and palate. Part V: The clinic and the multidisciplinary approach to cleft lip and palate cases. J.Dent.Assoc.S.Afr. 1984;39(8):543-45.

9. Dawjee SM, Julyan JC, Krynauw JC. Lip tape therapy in patients with a cleft lip-a report on eight cases. J.Dent. Assoc.S.Afr. 2014;69(2):62, 64-8, 70.

10. Jorgenson RJ, Shapiro SD, Odinet KL. Studies on facial growth and arch size in cleft lip and palate. J.Craniofac.Genet. Dev.Biol. 1984;4(1):33-8.

11. Choo H, Maguire M, Low DW. Modified technique of presurgical infant maxillary orthopedics for complete unilateral cleft lip and palate. Plast.Reconstr.Surg. 2012;129(1):249-52.

\section{Do the CPD questionnaire on page 153}

The Continuous Professional Development (CPD) section provides for twenty general questions and five ethics questions. The section provides members with a valuable source of CPD points whilst also achieving the objective of CPD, to assure continuing education. The importance of continuing professional development should not be underestimated, it is a career-long obligation for practicing professionals.

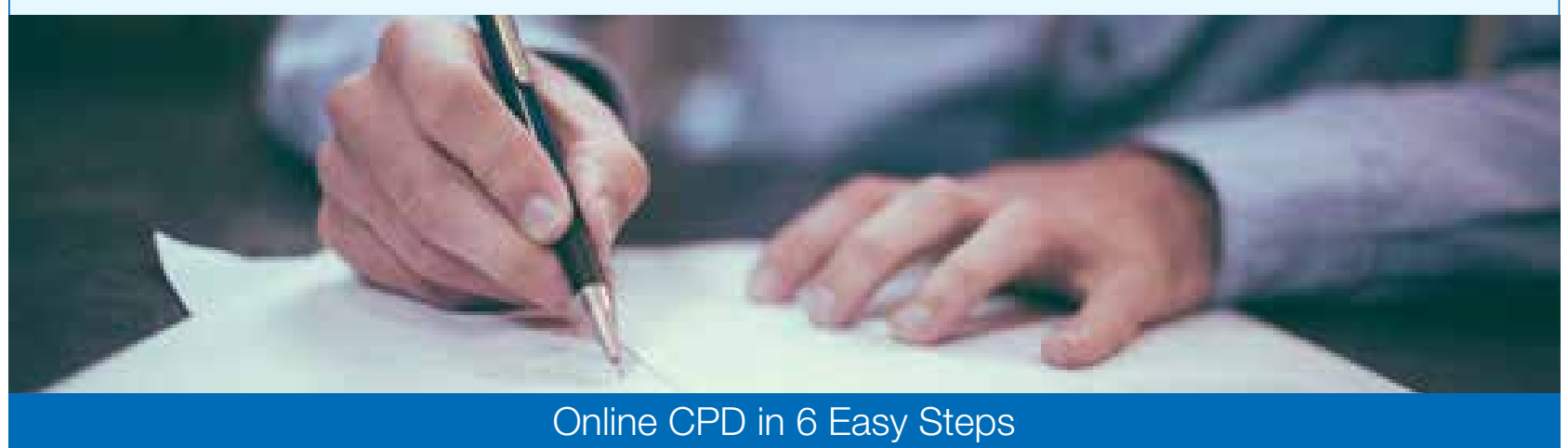

Go to the SADA website www.sada.co.za.

2 Log into the 'member only' section with your unique SADA username and password.

3 Select the CPD navigation tab.

4 Select the questionnaire that you wish to complete.

5 Enter your multiple choice answers. Please note that you have two attempts to obtain at least $70 \%$.

$6 \quad$ View and print your CPD certificate. 